\title{
Passive Case Search
}

National Cancer Institute

\section{Source}

National Cancer Institute. Passive Case Search. NCI Thesaurus. Code C127516.

Finding subjects with a particular characteristic or disease without actively searching. 